\section{PLIO-PLEISTOCENE}

\section{Magnetic Definition}

from our Geomagnetism Correspondent

Although much work has been done on the geomagnetic stratigraphy of deep sea sediment cores, very few similar studies have been made of marine sediments now exposed on land. The reason for this is partly because land-based sediments have often been subjected to uplift and erosion (which complicates palaeomagnetic measurements), partly because exposed sections are not usually very long and partly because continental sediments seem to be far more prone to chemical alteration than their deep sea counterparts. Yet, as Kennett et al. have demonstrated (Science, 171, 276; 1971), a good land section of sedimentary rock offers the opportunity not only for magnetic stratigraphy determination but also for correlation with geological stratigraphy and palaeoclimatic indicators and for throwing some light on that vexed question of where to place the Plio-Pleistocene boundary.

The geological controversy aroused by the Plio-Pleistocene boundary in the past century is one of those things which most geophysicists find incomprehensible. Indeed, in this age of the radiometric date, the so-called absolute date, it is difficult to see why what is, after all, an arbitrary nomenclature really matters. That it matters to geologists would seem to be a hangover from the days when the chief contribution of geology was to place a seemingly infinite number of unrelated facts into some sort of manageable framework. The irony is, of course, that although geophysicists care very little where the Plio-Pleistocene boundary is, or whether it should exist at all, it is geophysical measurement which is now making a much more precise-and, dare one say it, sensible-definition of this boundary possible.

And so to Kennett et al., who have been proving this very point by measuring the magnetic stratigraphy of a section of Pliocene and Pleistocene sediments in New Zealand. Comparison of the magnetic reversal pattern over the past three million years with that determined from continental rocks has enabled an absolute chronology to be placed on this particular sedimentary sequence the oxygen isotope and foraminiferal palaeotemperature curves of which had already been determined by Devereux et al. (Earth Planet. Sci. Lett., 8, 163; 1970). Using the new chronology it is now possible to see that the first major Pliocene cooling occurred 2.50 to 2.30 million years ago (spanning the GaussMatuyama magnetic boundary), that the second coincides with the lower part of the Olduvai event ( 2.13 to 2.10 million years ago) and that a third cooling (1.98 to 1.88 million years)

correlates with the upper part of the Olduvai.

The implications of the new magnetic data for the position of the Plio-Pleistocene boundary are necessarily involved and not easily stated in a few words. But the situation is basically this. The Plio-Pleistocene boundary in New Zealand has been defined in two waysclimatically, based on the first severe cooling, and stratigraphically, based on correlation with the Calabrian stage in southern Italy. As far as the climatic definition is concerned, Kennett's new chronology clearly shows that the first major cooling took place about 2.5 million years ago and thus on any reasonable scheme falls in the Middle Pliocene. To be sure, this begs the question of how the Pliocene is defined in the first place; but taking geological and palaeontological constraints into

\title{
Microseisms and Storms at Sea
}

Microseisms are smalt tremors in the Earth's surface with amplitudes of up to $10 \mu \mathrm{m}$; those of frequency 0.1 to $0.5 \mathrm{~Hz}$ are very closely associated with sea waves near the coast or in a storm area up to 2,000 miles away. In next Monday's Nature Physical Science, T. D. Krishna Kartha describes his work on the variation of velocity (refraction) of microseisms approaching Cochin in southern India. Refraction diagrams have already been produced for the western approaches to the British Isles, the seas around Bermuda and the seas to the south of South Africa.

The frequency of microseisms is usually about twice that of the associated sea wave and increases near the coast as the swell frequency increases. For a long time it was not clear how sea waves out at sea could generate microseisms because the pressure of the sea wave vanishes at depths greater than half a wavelength (about 150-300 m). LonguetHiggins showed, however, that in the case of a stationary wave generated by two identical progressive waves travelling in opposite directions there is a second order pressure effect which does not vanish with depth and which fluctuates at twice the original wave frequency (Phil. Trans. Roy. Soc., A, 243, 1; 1950). This result was generalized to the interaction of waves of the same frequency but different amplitude, and it can be shown that there is still some second order effect when any two waves of equal frequency but different amplitudes and directions act together.

These conditions are clearly satisfied when swell is reflected off the coast, but they also exist in the case of a fast moving storm which can create sequences of account, all geologists would admit 2.5 million years as Pliocene. The climatic definition of the Plio-Pleistocene boundary in New Zealand is therefore wrong.

The correlation with the Calabrian type section in Italy is based on the first appearance of Globorotalia truncatulinoides which in New Zealand is now seen to coincide with the base of the Gilsa magnetic event at 1.79 million years. By comparison, the Plio-Pleistocene boundary within the Calabrian type section, based on the extrapolation of sedimentation rates, is 1.8 million years old. Thus, by what presumably amounts to a coincidence, the accepted type Plio-Pleistocene boundary can now also be defined in terms of magnetic stratigraphy. Clearly this will make it much easier to trace this boundary around the world. waves travelling in different directions.

Microseisms with the same frequency as the sea waves have also been detected recently; these are generated near the coast-where the wave pressure is still appreciable-but can be propagated over large distances. (It can be shown that even though the wavelength of the sea wave is usually less than $700 \mathrm{~m}$, the pressure effect spreads over a wide range of wavelengths including that of selismic waves (about $20 \mathrm{~km}$ ).)

Microseisms are of practical importance in predicting the onset of a storm in areas where meteorological observations are scarce as, for example, in the Pacific Ocean and the Indian Ocean; Kartha has dealt specifically with the latter. The microseism frequency gives the wave frequency and hence the wind speed in the storm; microseisms are also directional to some extent and, by using records of three components of ground movement, the azimuth of the storm can be found together with the actual position if two or three measuring stations are used. If the position of the storm is to be located, it is important to allow for refraction of the microseisms. Assuming that they are waves of the Stoneley type formed between the surface of the Earth and the sea, their velocities can be calculated; these seem to depend to a great extent on the sea depth, particularly if this is between 100 and 1,000 fathoms. Refraction diagrams can be drawn from the velocity measurement and these are useful not only to make corrections for direction of approach, but also to show up focusing or divergence effects and possibly to indicate that a storm acting from one direction is more powerful than one from another direction. 